\title{
APPLICATION OF VERTICAL FLAT THERMOSYPHON (VFT) AFFECTING ON PERFORMANCE ENHANCEMENT OF SPLIT TYPE AIR CONDITIONER
}

\section{KANTAPON PREMPRAYOON ${ }^{1}$, SAMPAN RITTIDECH $^{2} \&$ BOPIT BUBPHACHOT $^{3 *}$}

${ }^{I}$ Ph.D. student, Heat-Pipe and Thermal Tools Design Research Unit (HTDR), Department of Mechanical Engineering, Faculty of Engineering,

Mahasarakham University, Maha Sarakham, Thailand

${ }^{2}$ Professor, Office of the Higher Education Commission, Bangkok, Thailand

${ }^{3}$ Associate Professor, Heat-Pipe and Thermal Tools Design Research Unit (HTDR), Department of Mechanical Engineering, Faculty of Engineering, Mahasarakham University, Maha Sarakham, Thailand

\begin{abstract}
The vertical flat thermosyphon (VFT) technology has been used in various forms and is becoming more prevalent. They are used in conjunction with cooling coils in air conditioning units. The front side of the coil acts to reduce the temperature of the air and the rear side coil acts to increase high temperature. The cooling coils capability to condense the moisture will increase. The result is cooler than to recycle. This research project is to study the design, construct and compare the heat transfer rate, energy consumption, economic and statistical analysis, between before and after installation of closed loop oscillating heat pipe with check valves into cooling coils of split type air conditioner size of 12,000 BTU. The working fluids used in the experiment consists of three types as R134a, R410a and R22. Air velocity was $1.5,2.0$ and $2.5 \mathrm{~m} / \mathrm{s}$. The indoor design temperature was $25{ }^{\circ} \mathrm{C}$

The result of the design found that the air conditioning system sensible heat was $1.40 \mathrm{~kJ} / \mathrm{s}$ and latent heat was $1.295 \mathrm{~kJ} / \mathrm{s}$. The demand for re-heat was $423 \mathrm{~J} / \mathrm{s}$. The regression equations were used in this experiment to predict the theory heat transfer rate of dimensionless parameters was $431.20 \mathrm{~J} / \mathrm{s}$. Therefore lengths of the evaporator, the adiabatic and the condenser were 200,150 and $200 \mathrm{~mm}$ respectively. The experiment found that the working fluids of R134a were the average of the highest specific moisture condensation rate was $0.97 \mathrm{~kg} / \mathrm{kWh}$ at the air velocity of $2.5 \mathrm{~m} / \mathrm{s}$ (increased $18.57 \%$ ) and the average of specific heat transfer was $97.32 \mathrm{~kW} / \mathrm{m}^{2}$. The average coefficient of performance (COP) was 1.90 (increased 21.79\%), the average energy efficiency ratio (EER) was 6.47 (increased 21.39\%) and the average of electric power consumption was $1.62 \mathrm{kWh}$ which showed a decrease of $5.81 \%$.
\end{abstract}

KEYWORDS: Heat Pipe; Air Conditioner, Coefficient Of Performance, Energy Efficiency Ratio, Electricity Power Consumption

Received: Jun 08, 2020; Accepted: Jun 28, 2020; Published: Sep 18, 2020; Paper Id.: IJMPERDJUN20201322

\section{INTRODUCTION}

Thailand is a tropical country. Therefore the use of air conditioning systems has increased resulting in increased electricity consumption. Air conditioners are devices that use a lot of energy when compared to the energy consumption of other devices within the building. Therefore, increasing the efficiency of air conditioning systems affect to reduced energy used in the system and help reduce electricity consumption. The heat pipe is a powerful device that helps increase energy efficiency [1, 2]. In 2003, Martinez et al. [1] designed and experimental studied a mixed energy recovery system consisting of two heat pipes and indirect evaporative equipment for air conditioning. The energy characterization of the mixed energy recovery system was performed using experimental design 
techniques. From a result, it was found that by application of the mixed air-energy recovery system consisting of two heat pipes and indirect evaporative systems, part of the energy from the return airflow could be recovered, thus improving energy efficiency and reducing environmental impact. In 2010, Supirattanakul et al. [2] applied a closed-loop oscillating heat pipe with check valves (CLOHP/CV) on performance enhancement in a conventional air conditioning system. In this study, a closed-loop oscillating heat pipe with check valves (CLOHP/CV) was added to the cooling coil unit by circuiting heat pipes in sections before and after the cooling coil. From a result, the new cooling load had increased 3.6\%, the latter gave the highest value of $14.9 \%, 17.6 \%$ for COP and EER, respectively. The highest value of heat flux was $5.19 \mathrm{~kW} / \mathrm{m}^{2}$ with R134a was used as the working fluid. This equipment is difficult to manufacture, install, and maintain as shown in Figure 1.

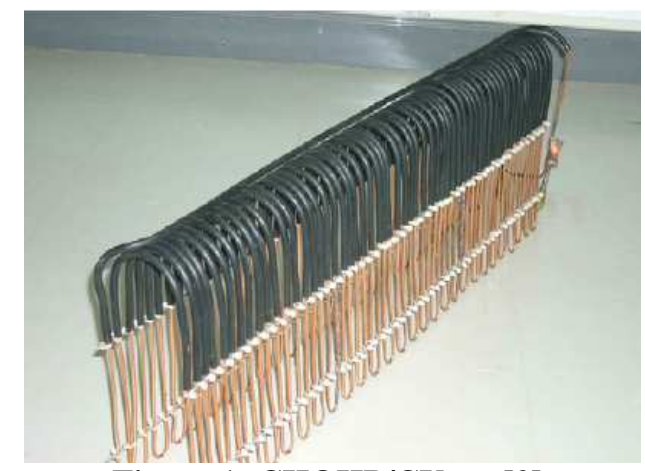

Figure 1: CHOHP/CV set [2]

We have therefore studied other types of heat pipes to help reduce the complexity to manufacture, install, and maintain. We found that the thermosyphon heat pipe is a type of heat pipe that can help reduce the difficulty of production and installation. From the study of related research, in 2010, Amatachaya et al [3] investigated the effects of cross-sectional geometries, filling ratio and aspect ratio on the thermal performance of thermosyphon at different rates of heat input. Two cross-sectional geometries of thermosyphon as circular and flat were used. Every cross-sectional geometry was charged with distilled water, different filling ratios, aspect ratios and heat input. The results indicated that a flat two-phase closed thermosyphon (FTPCT) had a higher average wall temperature in the evaporator section than that of a conventional twophase closed thermosyphon (CTPCT). In 2015, Renjith et al [4] studied the thermal performance of the flat thermosyphon with and without anodized inner surface. Experiments are conducted for the anodized and non-anodized flat thermosyphons at various inclination angles and fill ratios. The total thermal resistance of the anodized thermosyphon is reduced by $20 \%$ when compared to the non-anodized thermosyphon. The porous density of the anodized surface has increased by almost $90 \%$ than the porous density of the non-anodized surface. The maximum enhancement in heat transfer coefficients of the evaporator and the condenser in the anodized thermosyphon is $9 \%$ and $27 \%$ respectively when compared to the non-anodized thermosyphon at a heat flux of $49 \mathrm{~kW} / \mathrm{m}^{2}$. The performances of flat and circular anodized thermosyphons are compared and it found that the flat thermosyphon performed better than the circular thermosyphon. The heat transfer coefficient in the evaporator and the condenser of the flat thermosyphon is enhanced to $69 \%$ and $56 \%$ respectively when compared to the circular thermosyphon at a heat flux of $50 \mathrm{~kW} / \mathrm{m}^{2}$. In 2009, Srimuang et al [5] presented an experimental investigation on the heat transfer characteristics of a vertical flat thermosyphon (VFT). Several tests were performed to assess the effects of filling ratios, hydraulic radius, working fluid, and aspect ratio (Le/4HR) at a vertical orientation on the heat transfer characteristics of the VFT. It was found that the filling ratios and hydraulic radius affect heat flux; while the aspect ratios of the VFT increased, the heat flux decreased. In addition, the working fluid 
changed from water and ethanol to R123 as the heat flux increases. In 2010, Rittidech et al [6] conducted to determine the effect of dimensionless parameters on heat-transfer characteristics of the vertical flat thermosyphon (VFT). The VFT used in this study employed a copper tube with an inner diameter of $8.6 \mathrm{~mm}$. The cross-sectional areas of the tube were reduced by pressing them into a mold at pressed thicknesses of 6.6, 4.6 and $2.6 \mathrm{~mm}$. The evaporator, adiabatic and condenser were similar in lengths of $0.13,0.23$ and $0.33 \mathrm{~m}$, respectively. The working fluids used were R123, ethanol and water with filling ratios of $20 \%, 40 \%, 60 \%$ and $80 \%$ of the total volume. The evaporator section was heated with hot water while the condenser section was cooled with water. When the system reached an appropriate flow rate volume, the temperatures of the cooling water were recorded in order to calculate the heat-transfer rate of the VFT. After this, the dimensionless parameter relationships were analyzed from the experimental results. After the study processes were completed, a correlation of the dimensionless parameters for predicting the VFT heat-transfer rate was established.

Therefore, in this study, the vertical flat thermosyphon (VFT) heat pipe was added to the cooling coil unit by circuiting heat pipes in sections before and after the cooling coil as shown in Figure 2. The objective of this research was to study the application and working fluid type of the VFT heat pipe on energy consumption in the split type air conditioner system.

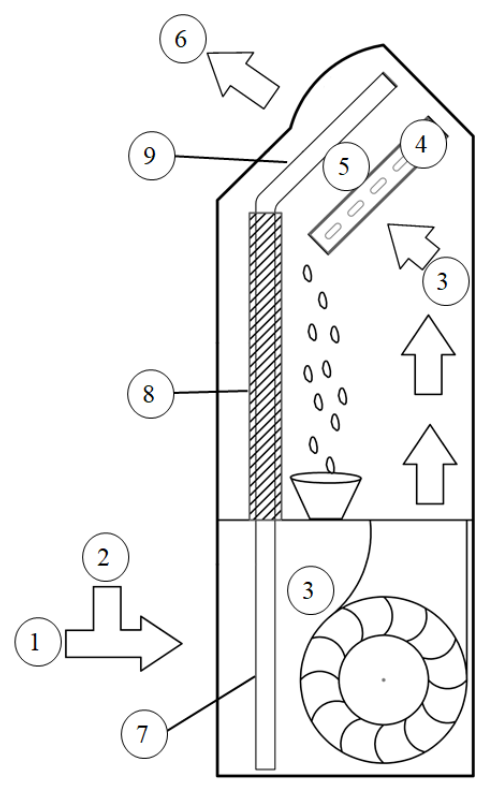

Figure 2: Arrangement of the VFT set. (1) Outdoor air, (2) return air, (3) pre-cooled air, (4) cooling coil, (5) cooled and dehumidified air, (6) reheated air, (7) evaporator section, (8) insulator and (9) condenser section

\section{MATERIALS AND METHODS}

\subsection{Experimental setup}

The system was made of a copper tube with an inside diameter of $8.6 \mathrm{~mm}$ and $0.46 \mathrm{~mm}$ thickness. The copper tube of 8 tubes were squeezed to a cross-sectional area of the y-axis with a distance of $4.6 \mathrm{~mm}$ and the $\mathrm{x}$-axis with a distance of 6.28 $\mathrm{mm}$ [5], shown in Figure 3. The result of the design found that the air conditioning system sensible heat was $1.40 \mathrm{~kJ} / \mathrm{s}$ and latent heat was $1.295 \mathrm{~kJ} / \mathrm{s}$. The demand for re-heat was $423 \mathrm{~J} / \mathrm{s}$. The regression equations were used in this experiment to predict the theory heat transfer rate of dimensionless parameters was $431.2 \mathrm{~J} / \mathrm{s}$ [6]. Therefore lengths of the evaporator, the adiabatic and the condenser were 200, 150 and $200 \mathrm{~mm}$ respectively shown in Figure 4 and the photograph of the VFT in 
this study shown in Figure 5. The working fluid used as in the VFT set was R134a, R401a and R22 refrigerant. The pressure and temperature of the refrigerant of air conditioner were measured with pressure gages and type-K copper constant thermocouples. The test consisted of the air conditioning system, air conditioning room and data acquisition system. The air conditioner with 12,000 BTU/h was tested.

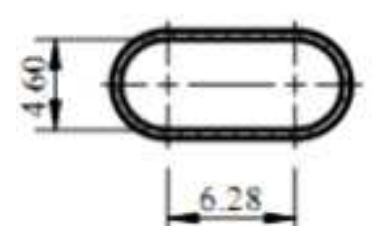

Figure 3: Cross-section of the copper tube

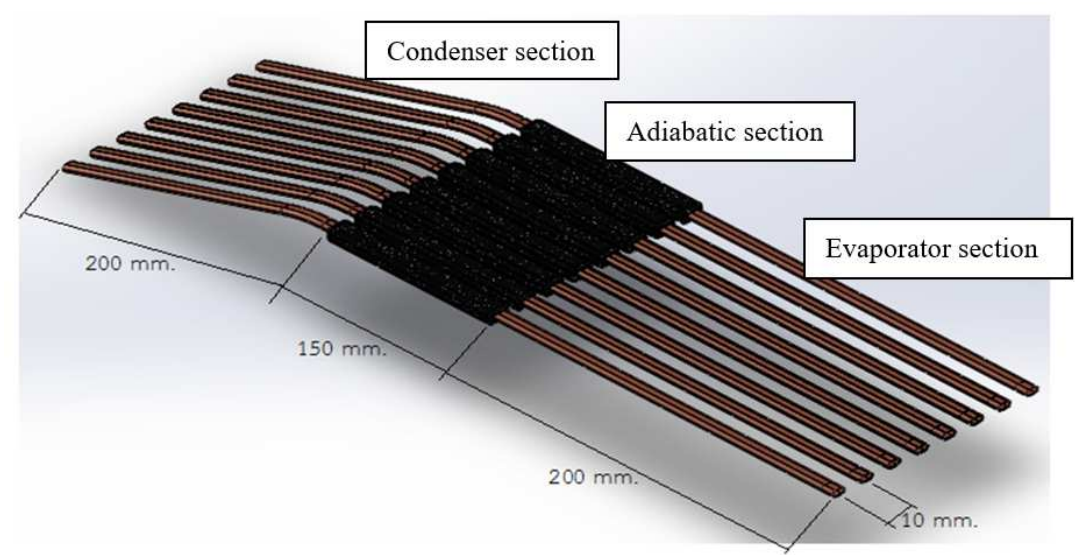

Figure 4: The VFT setup

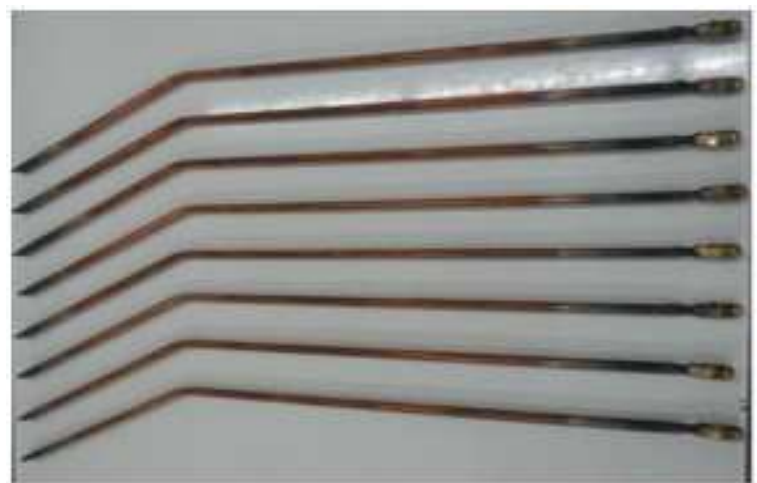

Figure 5: Photograph of the VFT

\subsection{Operating Condition}

The experiments were conducted in the period time of $8 h(08.30-16.30)$ in which the relevant parameters were recorded every $15 \mathrm{~min}$. The air conditioning temperature was set at the constant temperature of $25{ }^{\circ} \mathrm{C}$ throughout the experiment. The experimental procedure diagram was shown in Figure 6. The supplied voltage and current to the compressor were measured by the digital clamp meter. The temperatures at each position were recorded three times. Data collection was carried out using a data acquisition system (HIOKI 8422-01 with $\pm 0.2 \%, 20$ channel input, and -100 to 2,000 ${ }^{\circ} \mathrm{C}$ measurement temperature range). Temperatures at each position were averaged over the time period. 


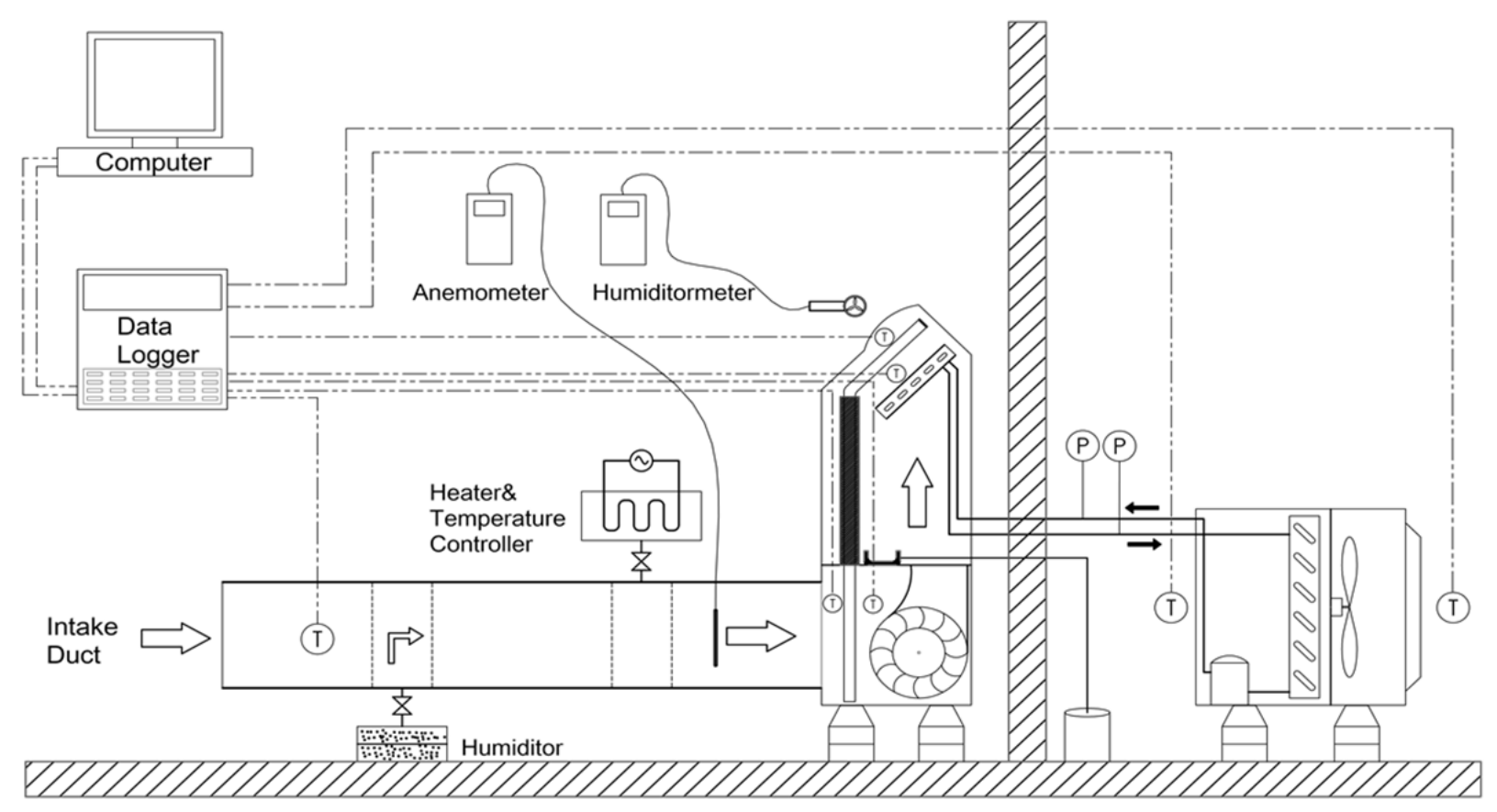

Figure 6: Experimental procedure diagram

\section{RESULTS AND DISCUSSIONS}

\subsection{The Average of Specific Moisture Condensation Rate}

Figure 7 shows the relation between air velocity and the average specific moisture condensation rate by not adding and adding the VFT. The experimental result found that hot air and humid were exchanged the heat with the cooling coil of the air conditioner, causing the temperature to drop at the dew point, the air will condense to become water droplets. The experimental result by not adding the VFT show the average of specific moisture condensation rate as $0.43,0.54$ and 0.70 $\mathrm{kg} / \mathrm{kWh}$ with the air velocity of $1.5,2.0$ and $2.5 \mathrm{~m} / \mathrm{s}$ respectively. The experiment found that the working fluids of R134a were the average of the highest specific moisture condensation rate of $0.97 \mathrm{~kg} / \mathrm{kWh}$ at the air velocity of $2.5 \mathrm{~m} / \mathrm{s}$ (increased $18.57 \%$ ). The experiment results by adding the VFT had the average specific moisture condensation rate higher than not adding the VFT in all conditions.

\subsection{The Average of Specific Heat Transfer Rate}

Figure 8 shows the relation between air velocity and the average specific heat transfer rate by adding the VFT on the different working fluids. The experimental result found that the working fluids of R410a show the average of the highest specific heat transfer rate as $153.14,153.7$ and $153.20 \mathrm{~kW} / \mathrm{mm}^{2}$ with the air velocity of $1.5,2.0$ and $2.5 \mathrm{~m} / \mathrm{s}$ respectively than all working fluids. 


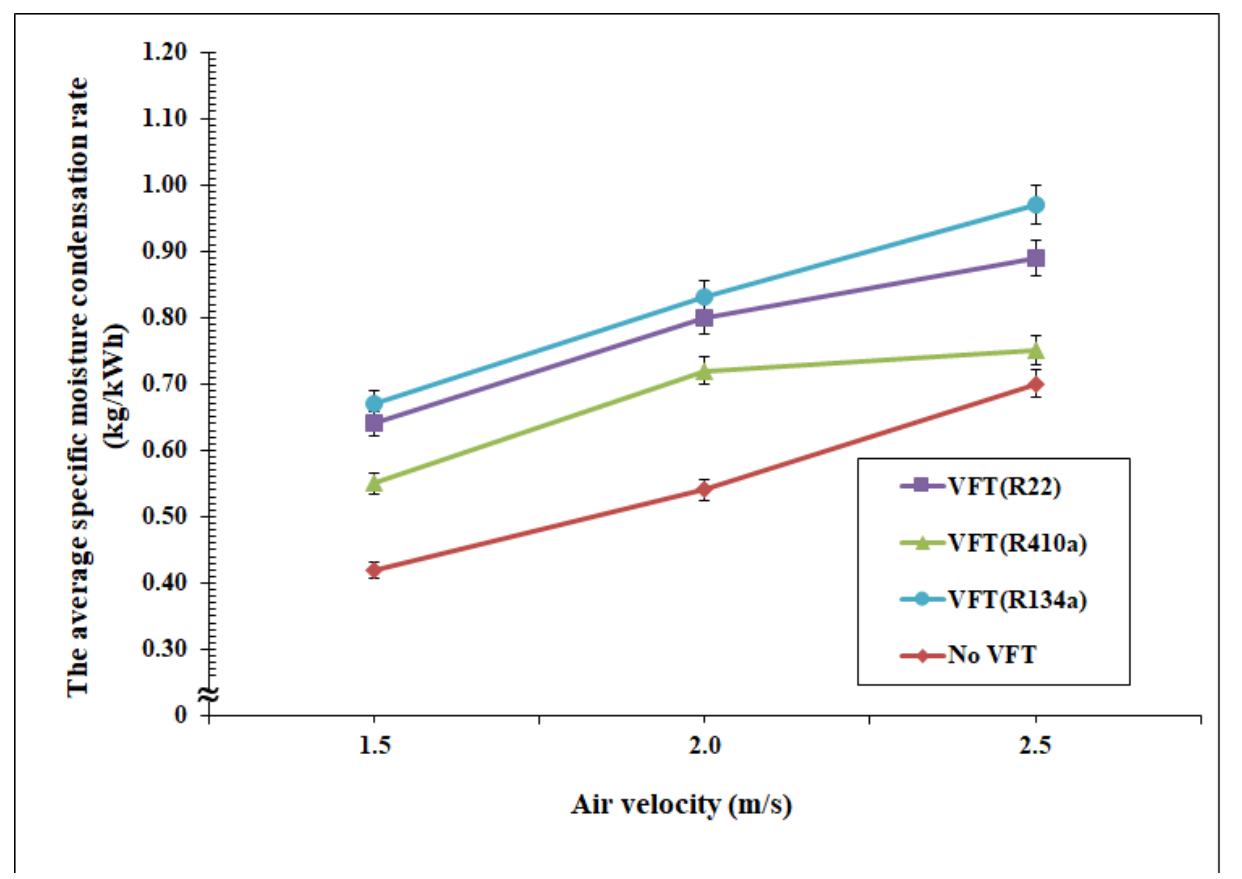

Figure 7: The relation between air velocity and the average specific moisture condensation rate

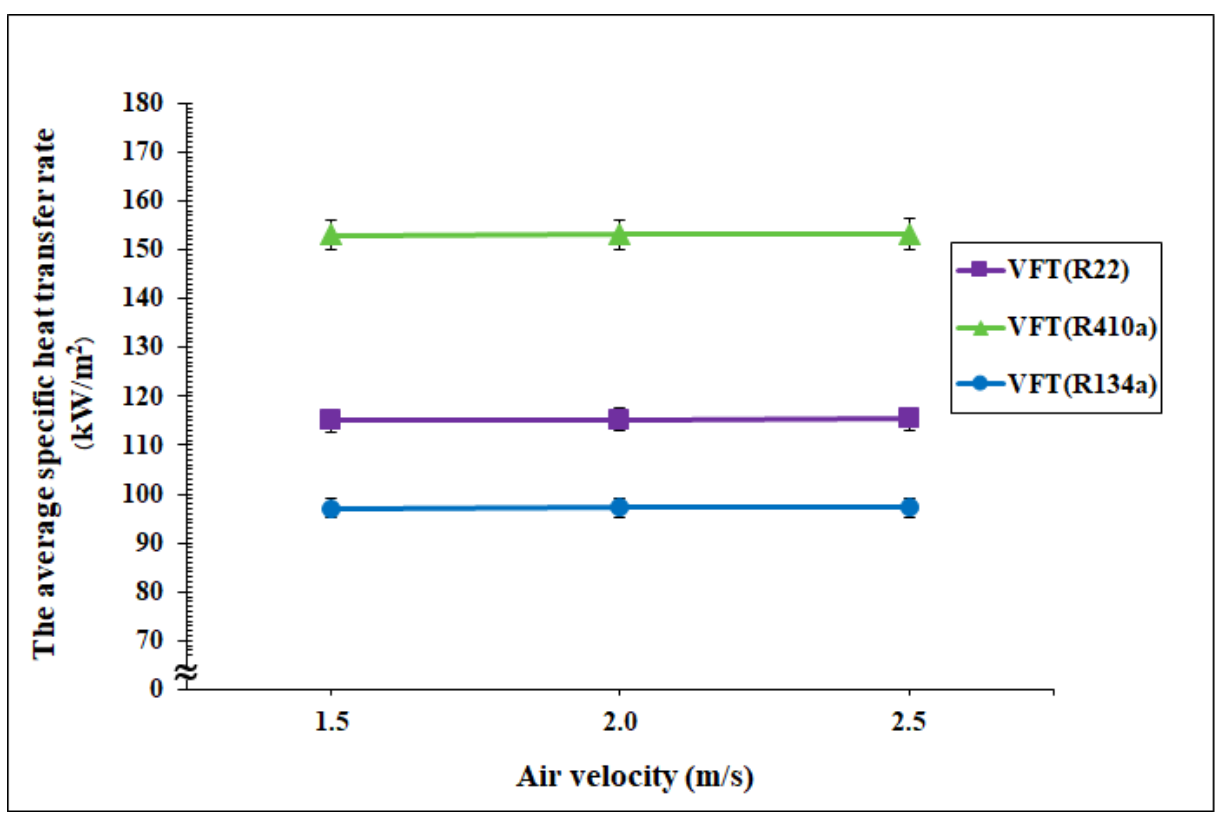

Figure 8: The relation between air velocity and the average specific heat transfer rate

\subsection{The Average Coefficient of Performance}

Figure 9 shows the relation between air velocity and the average coefficient of performance by not adding and adding the VFT. The experimental result by not adding the VFT show the average coefficient of performance as 1.17, 1.43 and 1.56 with the air velocity of 1.5, 2.0 and $2.5 \mathrm{~m} / \mathrm{s}$ respectively. The experiment found that the working fluids of R134a were the average of the highest coefficient of performance was 1.90 at the air velocity of $2.5 \mathrm{~m} / \mathrm{s}$ (increased $21.79 \%$ ). The experiment results with add the VFT had the average coefficient of performance higher than not add the VFT in all conditions. 


\subsection{The Average Energy Efficiency Ratio}

The relation between air velocity and the average energy efficiency ratio by not adding and adding the VFT shows in Figure 10. The experimental result by not adding the VFT show the average energy efficiency ratio as 4.01, 4.89 and 5.33 with the air velocity of 1.5, 2.0 and $2.5 \mathrm{~m} / \mathrm{s}$ respectively. The experiment found that the working fluids of R134a were the average of the highest energy efficiency ratio was 6.47 at the air velocity of $2.5 \mathrm{~m} / \mathrm{s}$ (increased 21.39\%). The experiment results with add the VFT had the average energy efficiency ratio higher than not add the VFT in all conditions.

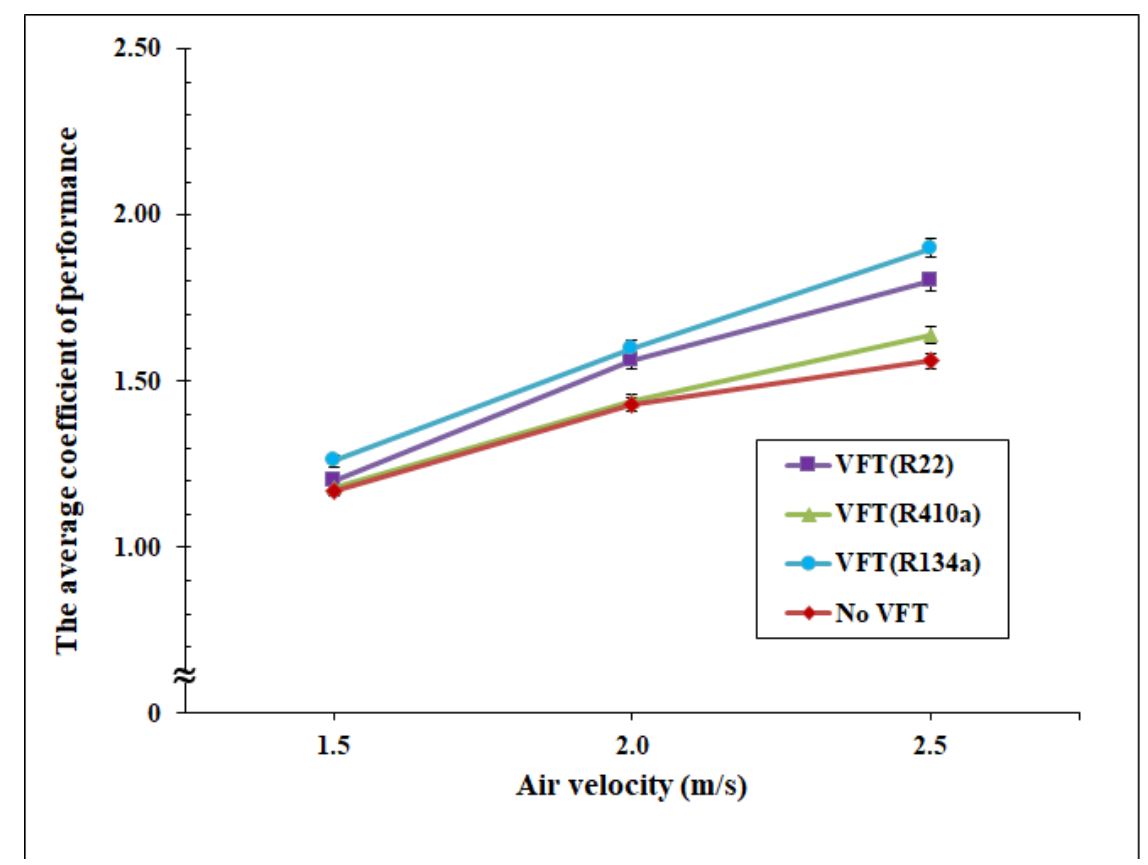

Figure 9: The relation between air velocity and the average coefficient of performance

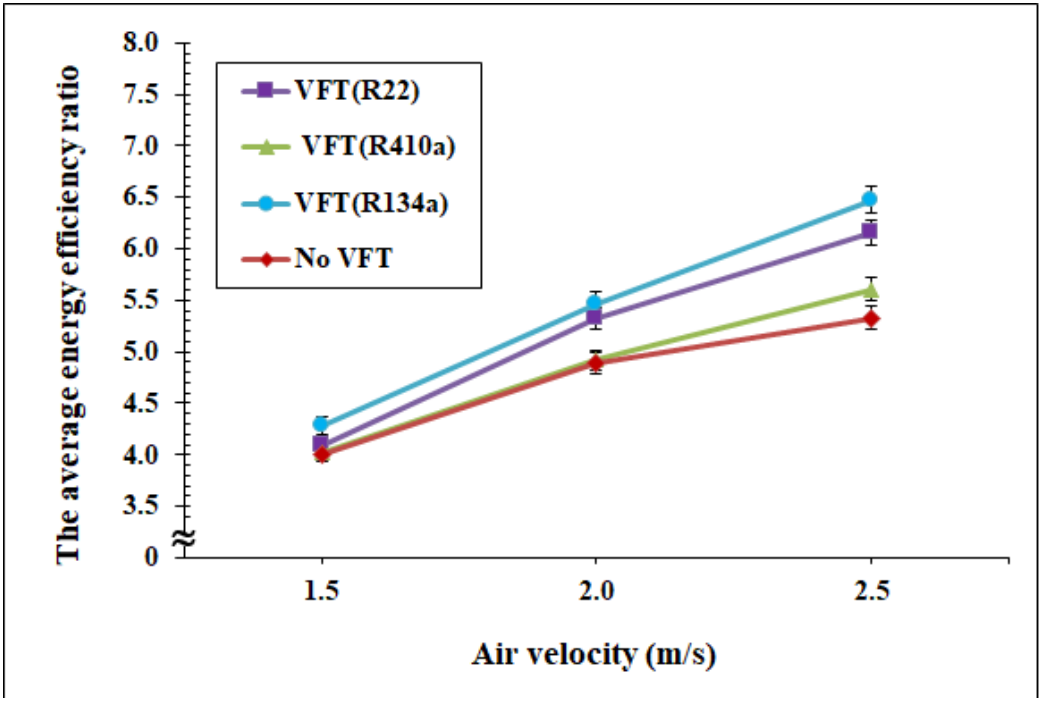

Figure 10: The relation between air velocity and the average energy efficiency ratio

\subsection{The Average of Electricity Power Consumption}

Figure 11 shows the relation between air velocity and the average electric power consumption by not adding and adding the VFT. The experimental result by not adding the VFT show the average electric power consumption as 1.72, 1.77 and $1.79 \mathrm{~kW} / \mathrm{h}$ with the air velocity of $1.5,2.0$ and $2.5 \mathrm{~m} / \mathrm{s}$ respectively. The experiment found that the working fluids of R134a 
were the average of the smaller electric power consumption was $1.62 \mathrm{~kW} / \mathrm{h}$ at the air velocity of $2.5 \mathrm{~m} / \mathrm{s}$ (decreased $5.81 \%$ ). The experiment results with add the VFT had the average electric power consumption smaller than not add the VFT in all conditions.

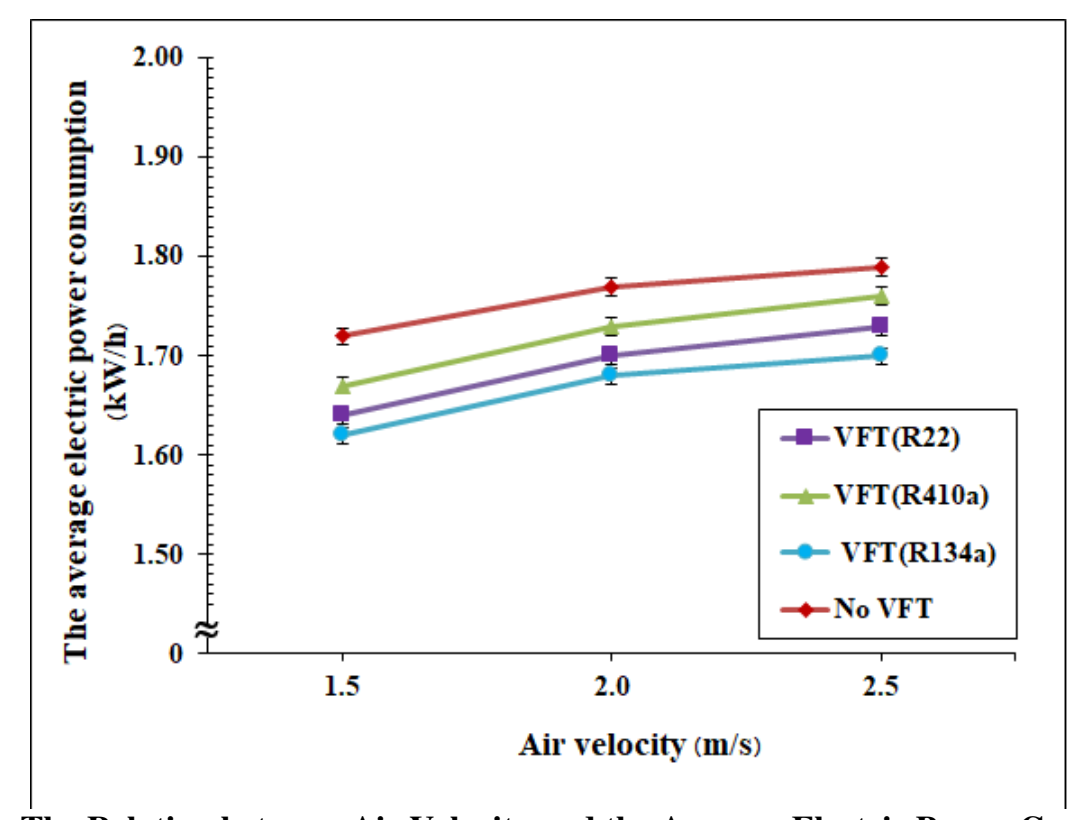

Figure 11: The Relation between Air Velocity and the Average Electric Power Consumption

\section{CONCLUSIONS}

This research project is to study the design, construct and compare the heat transfer rate, energy consumption, economic and statistical analysis, between before and after installation of closed loop oscillating heat pipe with check valves into cooling coils of split type air conditioner size of 12,000 BTU. The working fluids used in the experiment consists of three types as R134a, R410a and R22. The air velocity was $1.5,2.0$ and $2.5 \mathrm{~m} / \mathrm{s}$. The indoor design temperature was $25{ }^{\circ} \mathrm{C}$

The result of the design found that the air conditioning system sensible heat was $1.40 \mathrm{~kJ} / \mathrm{s}$ and latent heat was $1.295 \mathrm{~kJ} / \mathrm{s}$. The demand for re-heat was $423 \mathrm{~J} / \mathrm{s}$. The regression equations were used in this experiment to predict the theory heat transfer rate of dimensionless parameters was $431.20 \mathrm{~J} / \mathrm{s}[5,6]$. Therefore lengths of the evaporator, the adiabatic and the condenser were 200, 150 and $200 \mathrm{~mm}$ respectively. The results found that R134a was a better-working fluid used as in the VFT than R401a and R22. The conclusions were the following: 1) The R134a were the average of the highest specific moisture condensation rate was $0.97 \mathrm{~kg} / \mathrm{kWh}$ at the air velocity of $2.5 \mathrm{~m} / \mathrm{s}$ (increased 18.57\%). 2) The R134a were the average coefficient of performance (COP) was 1.90 (increased 21.79\%). 3) The R134a were the average energy efficiency ratio (EER) was 6.47 (increased 21.39\%). 4) The R134a were the average electric power consumption was $1.62 \mathrm{kWh}$ which showed a decrease of $5.81 \%$.

\section{ACKNOWLEDGEMENTS}

This research was financially support by Mahasarakham University grant year 2017. The authors would like to thank you for the equipment and tools support from the Heat-Pipe and Thermal Tools Design Research Unit (HTDR), Department of Mechanical Engineering, Faculty of Engineering, Mahasarakham University, Maha Sarakham, Thailand. 


\section{REFERENCES}

1. F.J.R. Martinez, M.A. Alvarez-Guerra Plasencia, E. Velasco Gomez, F.V. Diez, R.H.Martin, 2003. Design and experimental study of mixed energy recovery system, heat pipe and indirect evaporative equipment for air conditioning. Energy and Buildings, Vol. 35, Issue 10, pp. 1021-1030.

2. Supirattanakul, P., Rittidech, P., and Bubphachot, B., 2011. Application of a closed-loop oscillating heat pipe with check valves (CLOHP/CV) on performance enhancement in air conditioning system, Energy and buildings, Vol. 43, Issue 7, pp.15311535.

3. Amatachaya, P., Srimuang, W., 2010. Comparative heat transfer characteristics of a flat two-phase closed thermosyphon (FTPCT) and a conventional two-phase closed thermosyphon (CTPCT), International Communications in Heat and Mass Transfer, Vol.37, Issue 3, pp. 293-298.

4. Renjith, R., Selladurai, V., Ponkarthik,K., and Brusly Solomon A., 2015. Effect of anodization on the heat transfer performance of flat thermosyphon, Experimental Thermal and Fluid Science, Vol. 68, pp. 574-581.

5. Srimuang, W., Rittidech,S. and Bubphachot, B., 2009. Heat transfer characteristics of a vertical flat thermosyphon (VFT), Journal of Mechanical Science and Technology, Vol.23, pp.2548- 2554.

6. Rittidech, S., Srimuang, W., 2010. Correlation to predict heat-transfer characteristics of a vertical flat thermosyphon (VFT) at normal operating conditions, International Journal of Heat and Mass Transfer, Vol.53, Issues 25 -26, pp. 5984-5987.

7. Ahmadzadehtalatapeh,M., Yau, Y.H., 2011. The application of heat pipe heat exchangers to improve the air quality and reduce the energy consumption of the air conditioning system in a hospital ward-A full year model simulation, Energy and Buildings, Vol. 43, Issue 9, pp. 2344-2355.

8. El-Baky, M.A., Mohamed, M.M., 2007. Heat pipe heat exchanger for heat recovery in air conditioning, Applied Thermal Engineering, Vol. 27, pp. 795-801.

9. Naphon, P., 2010. On the performance of air conditioner with heat pipe for cooling air in the condenser, Energy Conversion and Management, Vol.51, Issue 11, pp. 2362-2366.

10. Velasco Gomez, F.V. Diez, R.H. Martin., 2003. Design and experimental study of mixed energy recovery system, heat pipe and indirect evaporative equipment for air conditioning, Energy and Buildings, Vol. 35, Issue 10, pp. 1021-1030.

11. Xiao, P., Peter, J., and Aliakbar., A., 1997. Application of heat pipe heat exchangers to humidity control in air-conditioning systems, Applied Thermal Engineering, Vol.17, Issue 6, pp.561-568.

12. Yau, Y.H., 2008. The use of a double heat pipe heat exchanger system for reducing energy consumption of treating ventilation air in an operating theatre-A full year energy consumption model simulation, Energy and Buildings, Vol. 40, Issue 5, pp. 917925.

13. Yau, Y.H., Ahmadzadehtalatapeh, M., 2010. A review on the application of horizontal heat pipe heat exchangers in air conditioning systems in the tropics, Applied Thermal Engineering, Vol. 30, Issue 2-3, pp.77-84. 


\section{AUTHOR PROFILE}

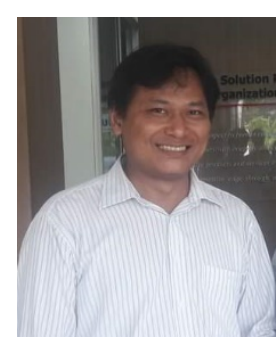

Mr. Kantapon Premprayoon received his B.Eng. degree in Mechanical Engineering (Manufacturing) from Mahasarakham University, Thailand, in 2008. He then received her M. Eng. degree in Mechanical Engineering from Mahasarakham University, Thailand, in 2011. Mr. Kantapon Premprayoon is currently a Ph.D. student in Mechanical Engineering at Mahasarakham University, Thailand.

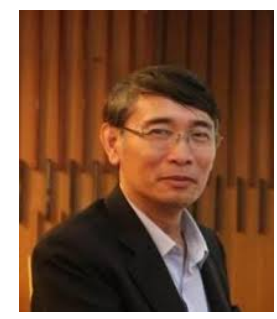

Mr. Sampan Rittidech received his Ph.D. degree in Mechanical Engineering from Chiang Mai University, Thailand in 2002. He is currently a Professor at Office of the Higher Education Commission, Bangkok, Thailand. His research interests include heat transfer, heat pipe, and heat exchanger.

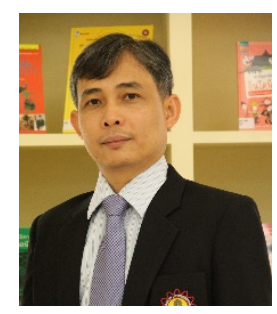

Mr. Bopit Bubphachot received his Ph.D. degree in Engineering Mechanics and Energy from University of Tsukuba, Japan, in 2008. Mr. Bopit Bubphachot is currently Associate Professor at the Faculty of Engineering at Mahasarakham University in Thailand. Mr. Bopit's research interests include Metal Forming (Fine Blanking Process), FEM Simulation in Metal Forming Process, Fatigue and Creep-Fatigue strength for Perforated Plate, Heat pipe, and Heat exchanger. 